\title{
LLDPE Kinetic properties estimation combining themogravimetry and differential scanning calorimetry as optimization targets
}

\author{
Alain Alonso ${ }^{1}$, Mariano Lázaro $^{1}$, Pedro Lázaro ${ }^{1}$, David Lázaro ${ }^{1}$, Daniel Alvear ${ }^{1}$ \\ ${ }^{1}$ GIDAI, University of Cantabria, Avda. Los Castros, s/n, 39005 Santander. Spain
}

\begin{abstract}
Thermal analysis techniques play a crucial role to characterize solid phase thermal decomposition, since it provides information about how mass is lost (Thermal Gravimetric Analysis) and energy released (Differential Scanning Calorimetry). However, most of the INPUT thermal parameters and kinetic properties to be used in fire computer modelling cannot be obtained directly from those tests. Early works looked forward achieving those parameters employing indirect fitting methods, which enable the user to obtain a set of parameters capable to simulate accurately the mass loss curve (TG) or its derivative (DTG).

This work aims to study the possibility of adding the energy released as a new target in the process, applying the analysis to Linear Low-Density Polyethylene (LLDPE). Results obtained in the present work reveal the major challenge of getting a set of parameters that can also fit DSC curve. The level of accuracy of the fitting to TG curve is higher than to DSC curve. This fact increases the value of the errors when both curves are used as targets to approach. As a result, this paper includes an alternative to consider the effects of the DSC curve.
\end{abstract}

\section{Keywords}

Thermal analysis, Thermal decomposition, fire computer models, optimization methods, LLDPE

\section{Nomenclature}

\begin{tabular}{|c|c|c|c|}
\hline$A$ & Pre-exponential factor $/ \mathrm{s}^{-1}$ & STA & Simultaneous thermal analysis \\
\hline$E_{a}$ & Activation energy $/ \mathrm{kJ} \cdot \mathrm{kmol}^{-1}$ & DTG & Derivative thermogravimetric analysis \\
\hline$n$ & Reaction order/- & MLR & Mass loss rate \\
\hline$H_{r}$ & Heat of reaction $/ \mathrm{kJ} \cdot \mathrm{kg}^{-1}$ & $\mathrm{DSC}$ & Differential Scanning Calorimetry \\
\hline$r$ & Reaction rate at temperature $T$ & FPA & Fire Propagation Apparatus \\
\hline$T$ & Temperature $/{ }^{\circ} \mathrm{C}$ & $M$ & Reacting material \\
\hline$\rho$ & Density $/ \mathrm{kg} \cdot \mathrm{m}^{-3}$ & $P$ & Submaterial generated as product of the reaction \\
\hline$C_{p}$ & Specific heat $/ \mathrm{kJ} \cdot \mathrm{kg}^{-1} \cdot \mathrm{K}^{-1}$ & $F$ & Fuel gas released by the reaction \\
\hline$k$ & Conductivity $/ \mathrm{W} \cdot \mathrm{m}^{-1} \cdot \mathrm{K}^{-1}$ & $G$ & Non-burning gas released by the reaction \\
\hline$\varepsilon$ & Emissivity/- & $R$ & Residue produced by the reaction \\
\hline$\eta$ & Absorption coefficient $/ \mathrm{m}^{-1}$ & $v_{p}$ & Amount of submaterial produced \\
\hline$Y_{s, i}$ & $\begin{array}{l}\text { Quotient between density of the material at } \\
\text { temperature } \mathrm{T} \text { divided by the initial density }\end{array}$ & $v_{f}$ & Amount of fuel gas released \\
\hline$r_{i j}$ & Reaction rate $/ \mathrm{kg} \cdot \mathrm{s}^{-1}$ & $v_{g}$ & Amount of non-burning gas released \\
\hline$v_{s i^{\prime} j}$ & Yield produced by the reaction $\mathrm{i}$ & $v_{r}$ & Amount of residue produced \\
\hline$r_{i^{\prime} j}$ & Residue produced by the reaction $\mathrm{i}$ & $X_{\text {error }}^{\text {curve }}$ & $\begin{array}{l}\text { Error between experimental and simulated } \\
\text { curves }\end{array}$ \\
\hline$\alpha$ & $\begin{array}{l}\text { Coefficient the conversion factor of } \\
\text { reactant/- }\end{array}$ & $\gamma$ & Influence of the TG curve over global error \\
\hline TG & Thermogravimetric analysis & $\beta$ & Influence of the DSC curve over global error \\
\hline
\end{tabular}

\section{Introduction}

Thermal decomposition processes are the key factor to understand the fire behaviour of materials and products. Thermal analysis techniques have been using widely for years [1] in order to obtain kinetic parameters and thermal properties that control thermal decomposition [2]. In addition, pyrolysis models combine mathematical equations that enables users to calculate the reactions of a thermal decomposition process. The Arrhenius equation is usually applied [3] in several simulation software packages, such as Gypro [4], ThermaKin [5], FireFOAM [6], Pyropolis [7], Fire Dynamics Simulator (FDS) [8] or TKS-SP software [9] [10], to calculate material mass loss in thermal decomposition process as a function of 
the temperature. Some major parameters to simulate the process involve the pre-exponential factor $(A)$, activation energy $\left(E_{a}\right)$, reaction order $(n)$, specific heat $\left(C_{p}\right)$, conductivity $(k)$, heat of reaction $\left(H_{r}\right)$.

Although thermal analysis techniques provides a useful framework to obtain the characterization of behaviour of materials in fire [11], most of the INPUT thermal parameters and kinetic properties for fire computer models cannot be obtained directly from those tests. To solve this gap, some authors have combined pyrolysis models and optimization methods, such as model-fitting [12-15], isoconversional methods [16-20] or genetic algorithms, etc. [21-23] to calculate these INPUT, which may be used in fire computer models. A detailed compilation of the employment of these techniques and methods can be found in [24].

Experimental results have to be used for this calibration process of fitting, as optimization targets, with the objective to find a set of parameters which succeed in simulating the experimental curves. While some studies selected the TGThermogravimetric results [23, 25, 26], others reproduced bench-scale tests, such as Fire Propagation Apparatus (FPA) or Cone Calorimetric. However, all of them were focused in the behaviour of the mass during the test (MLR-Mass Loss Rate) as optimization target $[6,27,28]$.

Since apart of the evolution of the mass as a function of the temperature, thermal analysis techniques can also quantify the energy released, hence, it seems logical that the next step should be to analyse extra features concerning the energy.

In this way, some works addressed specific efforts to consider the energy. Among then, we highlight the following works: in [29] a methodology for setting just heat of gasification is presented. The heat of gasification is the energy required to gasify a material and it is assessed using the Differential Scanning Calorimetry curve (DSC). The methodology was applied to common polymers and plastics. In [30] two types of experiments are used to evaluate the effect of decomposition kinetics for Fire Retardant Polyester Composite. First, three different kinetic models were adjusted to TG experimental curve and then the kinetic models were employed to reproduce Fire Propagation Apparatus (FPA) test. To compare the FPA modelled curves with the experimental ones, not only the mass loss rates were taken into account, also the energy was assessed by measuring the surface temperature of the sample. In [4] the pyrolysis model Gpyro was employed to reproduce the curves obtained from Cone Calorimetric tests of non-charring polymers, charring solids or intumescent coatings. To validate the model, the MLR experimental curves were compared with the simulated ones estimated by the model. Besides, other aspect related with the energy is evaluated, the surface temperature of the sample. The good correlations obtained by the model proves its validity. In the works [31] and [32] charring and non-charring polymers were analysed using TG and DSC tests. Both works employed a similar methodology, based on the utilization of the TG data acquire the thermal degradation kinetics. The kinetics properties were achieved by fitting of the Arrhenius parameters using the software Thermakin [5]. In addition, the heat capacities and the heat of melting of the polymers was calculated by using the information of DSC curves, however the DSC curve is not modelled by numerical methods as TG is. The study [33] presented a global studio, including several experimental techniques such TG, DSC and Controlled Atmosphere Pyrolysis Apparatus. These experiments were used to calibrate a proposed pyrolysis model. Kinetic data were obtained from TG curves using numerical methods implemented in the software Thermakin. As in [31] and [32], the DSC was used only to obtain the heat capacities and the heat of melting. As a novelty, thermal conductivities of the condensed-phase material components were measured and set by the employment of Controlled Atmosphere Pyrolysis Apparatus (CAPA) [34]. In [35] was presented a pyrolysis model for corrugated cardboard. The model is calibrated using the information from experimental tests such as TG, DSC and cone calorimeter. Thermogravimetric data was used as in [31-33]. Data from DSC was utilized, without using any numerical approaching method, to acquire the enthalpy of decomposition reactions the heat capacities of apparent species and the heat of combustion to the volatiles evolved from each reaction. Finally, cone calorimeter tests were used to measure the thermal transport properties within the sample. The characterization was carried out through an iterative inverse analysis. The work presented in [36] employed data from TG and DSC tests. While, TG curves combined with genetic algorithm were employed exclusively to estimate the kinetic properties, the DSC curve was used to identify the heat of pyrolysis peaks and quantify them.

To sum up, all these above-mentioned works $[4,29-33,35,36]$ utilize the information provided by DSC curves with the aim to achieve a more comprehensive and improved set of kinetic properties, even some of them e.g. [4] [33] [35], also employs bench-scale tests to analyse how the heat transfer is. Nevertheless, the data from DSC curves is not fully used as a target to approach the DSC simulated curve to the experimental one as the TG does. With this fact in mind, the present study aims to add the DSC curve as an additional target to approach by numerical methods. The use of numerical methods to fit TG and DSC curves simultaneously may well allow obtaining a more comprehensive set of properties since both mass and energy 
released are taking into account. As a case of study, we selected Linear Low-Density Polyethylene (LLDPE) to carry put the analysis.

The present paper is organized as follows: Experimental tests section presents the results from experimental STA tests; Simulation model section describes the simulation model elaborated; Optimization algorithm section give the details of the numerical approaching method employed; Results and discussion section exposes the results obtained; and finally the paper concludes with the Conclusion section with some indications for future work

\section{Experimental tests}

The Netzsch STA 449 F3 apparatus was used to perform the three experimental tests at three different heating rates (2, 5 and $10 \mathrm{~K} \cdot \mathrm{min}^{-1}$ ) with identical atmospheric conditions (inert atmosphere) to obtain experimental data. Testing in an inert atmosphere allows avoiding oxidative reactions [37]. The samples of LLDPE, with a density of $948.50 \mathrm{~kg} \mathrm{~m}^{-3}$ and an initial mass of 8.666, 9.744 and $9.924 \mathrm{mg}$ respectively, were prepared according to the ASTM-E1131-08 [38]. The samples were smashed to obtain small pieces, and after that, they were placed in a sample holder made of $\mathrm{Al}_{2} \mathrm{O}_{3}$.

Next Figure 1 shows the curves obtained in STA tests.

(a)

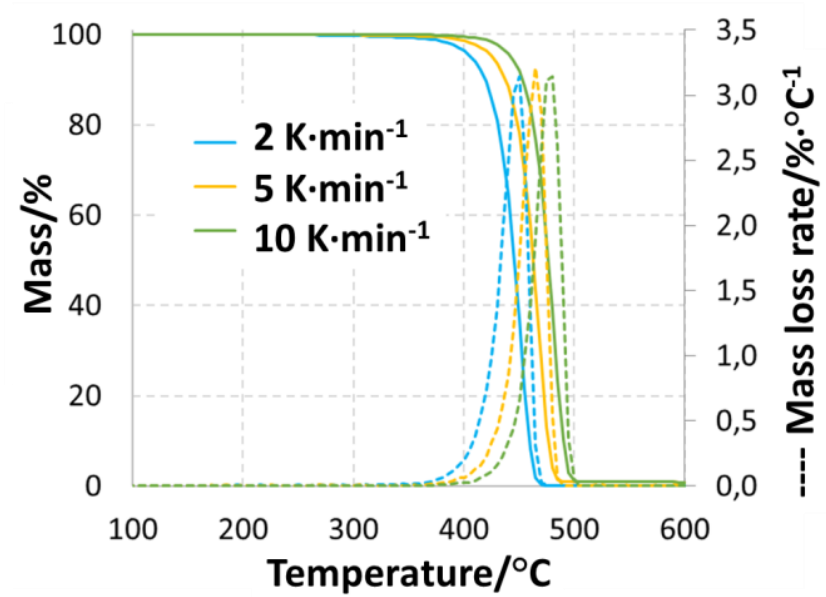

(b)

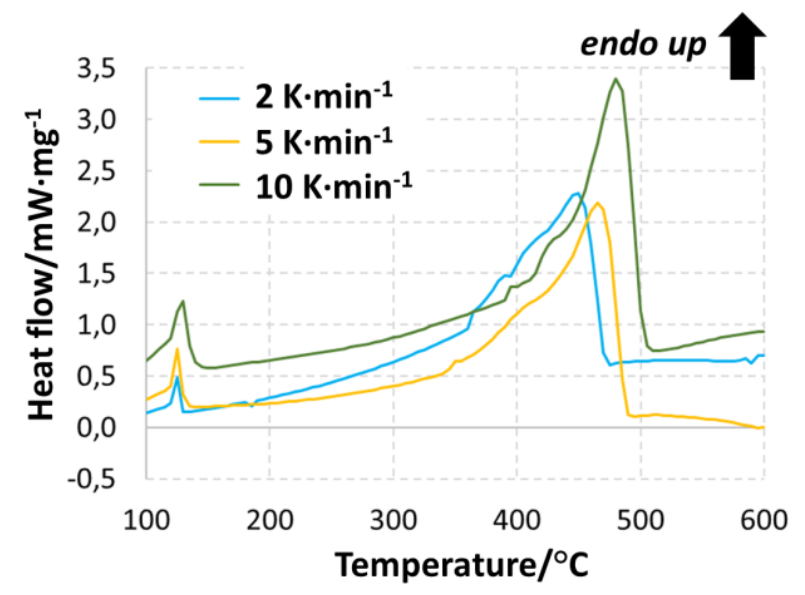

Fig. 1. Experimental curves: a TG and DTG, b DSC.

It is apparent from this figure that the three TG curves have same shape, only the onset temperature changes. The higher heating rate is employed for testing, the higher value for the onset $\left(422{ }^{\circ} \mathrm{C}, 437{ }^{\circ} \mathrm{C}\right.$ and $447{ }^{\circ} \mathrm{C}$ for 2,5 and $10 \mathrm{~K} \cdot \mathrm{min}^{-1}$ respectively). The peaks of the DSC curve occur at $455^{\circ} \mathrm{C}, 465^{\circ} \mathrm{C}$ and $486^{\circ} \mathrm{C}$ for 2,5 and $10 \mathrm{~K} \cdot \mathrm{min}^{-1}$, respectively. Since TG values showed similar results than other works with LLDPE in similar conditions [39, 40] these results were considered suitable for simulation purposes.

\section{Simulation model}

As we want to model either TG or DSC curves, it is required the use of a pyrolysis model and the definition of a reaction scheme. The present work selected the pyrolysis model employed by the software FDS [8], with a pyrolysis model based on the Arrhenius equation, which defines the mass loss rate as a function of the temperature. Next Eq. 1 shows the general evolution equation for a material undergoing one or more reactions.

$$
\frac{d Y_{s, i}}{d t}=\sum_{j=1}^{N_{r, i}} r_{i j}+\sum_{i=1}^{N_{m}} \sum_{j=1}^{N_{r, i^{\prime}}} v_{s i^{\prime} j} r_{i^{\prime} j}\left(i^{\prime} \neq i\right) ; Y_{s, i}=\left(\frac{\rho_{s, i}}{\rho_{s}(0)}\right)
$$

The term $Y_{s, i}$ represents the relationship between the density of the material $i$ produced by the reaction $j$ divided by the initial density of the material (prior to the reaction). The term $r_{i j}$ is the reaction rate at temperature $T_{s}$. The terms $v_{s i^{\prime} j} r_{i^{\prime} j}$ express the residue produced by the reaction $r_{i^{\prime} j}$ with a yield of $v_{s i^{\prime} j}$.

The value of $r_{i j}$ is calculated by Eq. 2 (Arrhenius equation): 


$$
r_{i j}=A_{i j} Y_{s, i}^{n_{s, i j}} e^{\left(-\frac{E a_{i j}}{R T_{S}}\right)} X_{O_{2}}^{n_{O_{2} i j}}
$$

Where $A_{i j}$ is the pre-exponential factor; $E a_{i j}$ is the activation energy and the terms $n_{s, i j}$ and $n_{O_{2} i j}$ are the reaction order. The term $X_{O_{2}}^{n_{O_{2} i j}}$ has null value, since it represents the effect of oxidative reaction.

$Y_{s, i}$ can be also written as a function of $\alpha$, the conversion factor of reactant, as in Eq. 3 is shown:

$$
\alpha=\frac{\left(m_{0}-m\right)}{m_{0}-m_{f}}
$$

Where $m_{0}$ is the initial mass prior the reaction begins, $m$ is the mass at temperature $T$, and $m_{f}$ is the mass when the reaction is over.

The Eq. 2 represented as a function of $\alpha$ is shown in Eq. 4:

$$
r_{i j}=\frac{d \alpha}{d t}=A_{i j} f(\alpha) e^{\left(-\frac{E a_{i j}}{R T_{S}}\right)}
$$

The term $f(\alpha)$ is the reaction mechanism [41]. FDS employs a reaction mechanism based on the reaction order, as Eq. 5 shows:

$$
f(\alpha)=(1-\alpha)^{N_{j}}
$$

Once the mass loss of the sample is modelled, it is necessary to represent the energy released by the tested sample. It can be assess using Eq. 6:

$$
\dot{q}_{s, c}^{\prime \prime \prime}(x)=-\rho_{0} \sum_{i=1}^{N_{m}} \sum_{j=1}^{N_{r, i}} r_{i, j}(x) \cdot H_{r, i j}
$$

Where $\dot{q}_{s, c}^{\prime \prime \prime}(x)$ is the energy released or absorbed by the reaction and it represents the heat of reaction $\left(H_{r}\right)$ from reaction $j$ and material $i$. Further details about pyrolysis model in FDS are given in [8].

Pyrolysis and thermal decomposition of LLDPE take place through multiple series of reactions [42-44]. In this work, the proposed reaction scheme is based on the hypothesis that supposes that there is a series of reactions, which governs the decomposition process. Among them, some have an enormous influence over the process. We consider these main reactions as the only ones that take place during the process, and the rest of reactions could be discarded due to their minimal influence. Following the idea of $[45,46]$, a methodology based on the employment of the second derivative of TG curve, i.e., the D2TG curve is used to determine the decomposition reactions. The local maxima/minima of D2TG curve correspond to the points where the mass loss rate curve changes its curvature drastically, hence, the points where exist a considerable variation in the reaction rate. These variations identify the moment when the decomposition process changes from one reaction to another. Consequently, the number of main reactions can be determined. It seems to be important to select a suitable level of complexity in the reaction scheme, i.e. the number of reactions. The higher number of reactions to describe the reaction, the higher number of the variables to be managed by the numerical approaching method. Therefore, on the one hand, a large amount of variables could slow down the approaching process without achieve a high accuracy level, and on the other hand, a few number of reactions could omit significant information.

Next Figure 2 represents the number of reactions proposed by this methodology. 


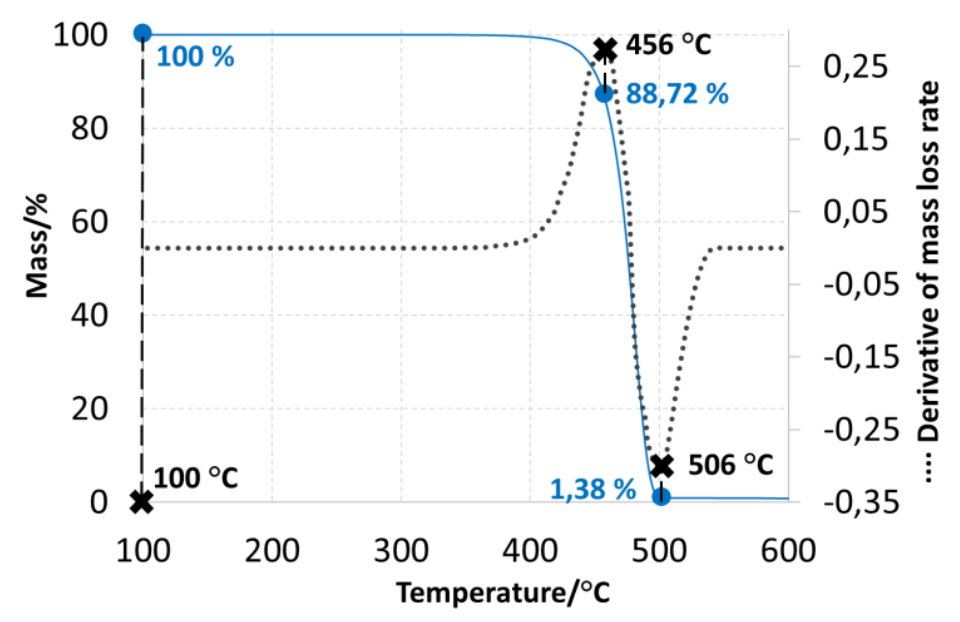

Fig. 2. Reaction scheme proposed by D2TG method applied to TG experimental curve obtained at $10 \mathrm{~K} \cdot \mathrm{min}^{-1}$.

The thermal decomposition model for the solid phase proposed in this work is the decomposition of the LLDPE that undergoes a decomposition process in two steps or two reactions, creating one intermediate fictitious material and a final residue. Each reaction produces a residue and releases gases, following the same idea proposed in [23, 32, 47]. The reaction scheme defined is a two-consecutive reaction scheme that FDS determines following the generic Eq. 7 :

$$
M^{i}+O_{2}^{i}+Q^{i} \stackrel{\operatorname{Reac} j}{\longrightarrow} v_{p}^{i} \cdot P+v_{f}^{i} \cdot F+v_{g}^{i} \cdot G+v_{r}^{i} \cdot R
$$

Where the terms are: $M$ the reacting material; $Q$ the heat necessary to trigger the reaction; $O_{2}$ the oxygen consumed by reaction ( 0 value in this case due to the lack of oxygen in the test). The products produced are: $P$ the amount of submaterial created as product of the reaction; $F$ the fuel gas released, $G$ the non-burning gas released (e.g. water vapour), and finally, $R$ is the residue. The coefficients $v_{p}^{j}, v_{f}^{j}, v_{g}^{j}$ and $v_{r}^{j}$, indicate the amount of each product created in reaction $j$. It is considered that there is non-burning gas released, i.e. $v_{g}^{i}$ is zero. Next Eq. 10 and Eq. 11 gathers the reaction scheme employed:

$$
\begin{aligned}
A+ & Q^{1} \stackrel{\text { Reac } 1}{\longrightarrow} v_{p}^{1} \cdot B+v_{f}^{1} \cdot \text { Fuel gas } \\
& \quad B+Q^{2} \stackrel{\text { Reac } 2}{\longrightarrow} v_{r}^{2} \cdot \text { Residue }+v_{f}^{2} \cdot \text { Fuel gas }
\end{aligned}
$$

Once the reaction scheme is established, next step is to define which variables are involved in the process. The values of these variables will be determine by the numerical approaching method. These variables are: pre-exponential factor $(A)$, activation energy $\left(E_{a}\right)$, reaction order $(n)$ i.e. the triplet kinetic that appears in Eq. 4 and Eq. 6 . In Eq. 6 appears the heat of reaction $\left(H_{r}\right)$. As well as these properties, the model configured includes the next thermal parameters: density $(\rho)$, specific heat $\left(C_{p}\right)$, conductivity $(k)$, emissivity $(\varepsilon)$. The density of each material and submaterial $(\rho)$ are related with the coefficients of Eq. 10 and Eq. 11. The relationship between them are: $v_{p}^{1}+v_{f}^{1}=1$ for Eq. 10 , and $v_{r}^{1}+v_{f}^{1}=1$ for Eq. 11 . In total, there are 18 values of its corresponding variables to achieve by the numerical method.

As result of the small size of the samples employed, both reactions are considered to take part in the surface of the sample, i.e. absorption coefficient $(\eta)$ is constant and with a high value $(9 \mathrm{e}+8)$.

\section{Optimization algorithm}

We selected the Shuffled Complex Evolution- University of Arizona (SCE-UA, from now on SCE) numerical approaching method to achieve the values of the input variables that are able to fit the target experimental curve. The SCE method was developed and applied successfully for the first time to find a global optimum of a conceptual rainfall-runoff model [48]. Nevertheless, in recent years this method have been using to elaborate and optimize models in several areas of engineering e.g. in transportation $[49,50]$, in geology $[51,52]$ or in fire safety engineering $[23,53]$.

SCE numerical method is based on a synthesis of four concepts that have been proved successful for global optimization: combination of probabilistic and deterministic approaches; clustering; systematic evolution of a complex of points spanning 
the space in the direction of global improvement; and competitive evolution [54]. SCE-UA is based on the optimization method [55].

The main aim of SCE is to converge the value of a function defined by the user towards a global minimum. The function to minimize in this work is the evaluation error function represented in Eq. 12, which assess the error produced in the approach of TG and DSC signals, from the initial to the final temperature of the simulation.

$$
\text { Evaluation error function }=\sqrt{\left(\gamma \cdot \hat{X}_{\text {error }}^{T G}\right)^{2}+\left(\beta \cdot \hat{X}_{\text {error }}^{D S C}\right)^{2}}
$$

The coefficients $\gamma$ and $\beta$ are utilised to give a relative importance either curves, TG or DSC, from Eq. 12, i.e. to assume more relevance or not to the DSC curve, and figure out its influence on the analysis. Whereas the $X_{\text {error }}^{\text {curve (described in Eq. }}$ $13)$ is the mathematical operator used to evaluate the difference between experimental curves $\left(x_{i, \text { exp }}\right)$ and simulated curves $\left(x_{i, \text { sim }}\right)$. Due to the scale of the magnitudes measured, to establish a suitable comparison between both signals, the values from Eq. 13 are normalized ( $\hat{X}_{\text {error }}^{\text {curve }}$ ). To normalize them, a value of 1 is given to the highest error of each signal obtained ( $X_{\text {error }}^{\text {curve }}$ ) As Figures $1 \mathrm{~b}$ and Figure 4a, highest errors are produced in case 1 and case 2 for DSC and TG signal respectively.

$$
X_{\text {error }}^{\text {curve }}=\frac{\sqrt{\sum_{i}\left(x_{i, \text { exp }}-x_{i, s i m}\right)^{2}}}{n}
$$

The term $n$ is the number of points measured

SCE requires an initial range of values for each parameter to initiate the approaching process. Despite of the algorithm will finish finding the values that minimizes the error function within that range of values, the wider is initial range, the more time will take it. Next Table 1 summarizes the initial values employed by the SCE. Some values come from experimental tests and other values are obtained from literature. Those values taken as reference were increased and decreased properly to establish a reasonable wide range of values.

Table 1. Initial range of values to start the numerical approaching process

\begin{tabular}{llll}
\hline Variable & Lower Value & Upper Value & Source \\
\hline Pre exponential factor $(\log 10 A) / \mathrm{s}^{-1}$ & 7.00 & 17 & {$[40]$} \\
Activation energy $\left(E_{a}\right) / \mathrm{kJ} \cdot \mathrm{kmol}^{-1}$ & $1.4 \mathrm{e}+5$ & $2.8 \mathrm{e}+5$ & {$[42]$} \\
Reaction order $(n) /-$ & 0.10 & 4.00 & \\
Heat of reaction $\left(H_{r}\right) / \mathrm{kJ} \cdot \mathrm{kg}^{-1}$ & -1000 & 200 & $\mathrm{a}$ \\
Mass $v_{i} / \mathrm{kg}$ & 0.01 & 0.99 & \\
Specific heat $\left(C_{p}\right) / \mathrm{kJ} \cdot \mathrm{kg}^{-1} \cdot \mathrm{K}^{-1}$ & 1.50 & 3.50 & {$[56]$} \\
Conductivity $(k) / \mathrm{W} \cdot \mathrm{m}^{-1} \cdot \mathrm{K}^{-1}$ & 0.18 & 0.40 & {$[57]$} \\
Emissivity $(\varepsilon) /-$ & 0.80 & 1.00 & $\mathrm{a}$ \\
\hline
\end{tabular}

a Values measured in laboratory tests. The value of the heat of reaction was $-792 / \mathrm{kJ}^{\circ} \mathrm{kg}^{-1}$ and 0.998 was the value of the emissivity at $45^{\circ} \mathrm{C}$.

The employment of programming code that synchronizes FDS and SCE allows finding the values of the variables that minimizes the error function. In essence, the process could be described as: 1) SCE selects the values for the different input variables of FDS; 2) the programing code employs these values to write an FDS input file following the reaction scheme proposed and execute it; 3 ) the results of the simulated case are evaluated according to evaluation error function (Eq. 12); and 4) in case of the error does not achieve the criteria to stop the iterative process, SCE changes the values according to its mode of operation and the process restart again. Two criterions were selected to stop the repetitive process considering that the SCE has found the minimal error: the number of iterations could not be more than 30000 , or in case of after five consecutive loops, the value Eq. 12 changes less than $5 \%$.

\section{Results and discussion}

In order to assess the influence of the TG and DSC curves as approaching target, we defined distinct importance relatives for both curves through a combination of the coefficients $\gamma$ and $\beta$. Firstly, the fitting target was the TG curve exclusively, 
and then, the DSC is included with a progressive influence over the error in Eq. 12. Next Table 2 shows the values of the coefficients used.

Table 2. Cases and values of the different coefficients of $\gamma$ and $\beta$

\begin{tabular}{lll}
\hline Case & Influence of TG, $\gamma$ & Influence of DSC, $\beta$ \\
\hline 1 & 1.0 & 0.0 (only TG curve is assessed) \\
2 & 0.5 & 0.5 \\
3 & 0.7 & 0.3 \\
4 & 0.9 & 0.1 \\
\hline
\end{tabular}

All these cases are compared exclusively with the experimental curves obtained under an external heating rate of $10 \mathrm{~K} \cdot \mathrm{min}^{-}$ ${ }^{1}$. Once the influence of DSC curve is known, the study is extended to the three heating rate tested $\left(2,5\right.$ and $\left.10 \mathrm{~K} \cdot \mathrm{min}^{-1}\right)$.

Case 1, which models only the TG curve with the purpose to assess the reaction scheme proposed is helpful evaluate how the impact of DSC fitting is. Figure 3 shows the results of case 1.

(a)

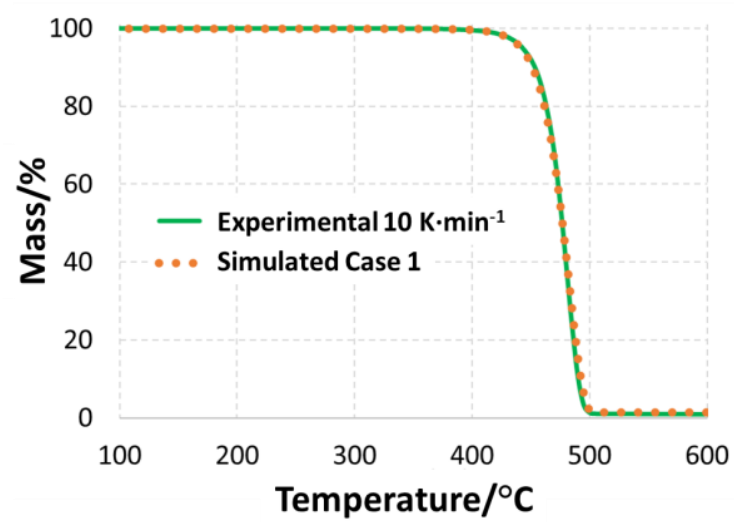

(b)

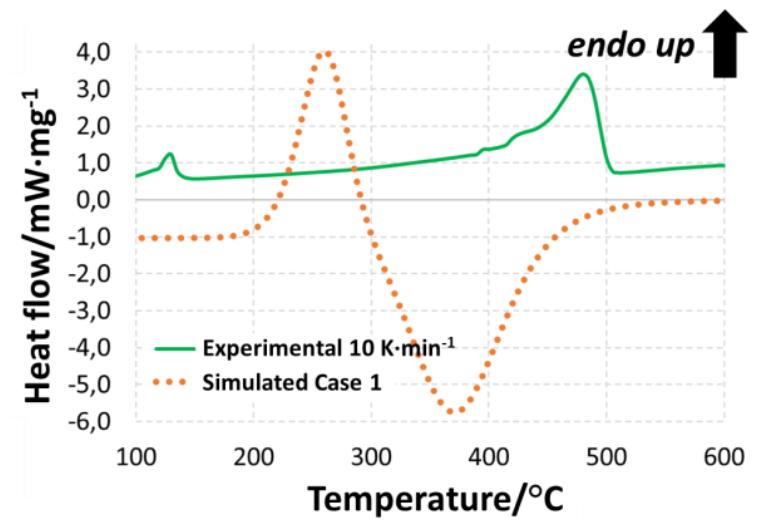

Fig. 3. Results of case 1: a TG, b DSC.

The simulated TG curve was obviously bound to reproduce with a reasonably level of accuracy the experimental curve. On the other hand, the fact of exclude the DSC curve from Eq. 12 leads to unfit DSC curve (Figure $3 \mathrm{~b}$ ) and the highest value is produced. The values of the normalized errors evaluated with Eq. 13 are $\hat{X}_{\text {TGA error }}^{\text {case } 1}=0.035$ and $\hat{X}_{D S C \text { error }}^{\text {case }}=1.00$.

Cases 2 to 4 insert in different degrees the error from DSC the mathematical operator of Eq. 13, to the global error function Eq. 12. Hence, the improvement of the error can be observed gradually. Next Figure 4 shows the results of these cases. Next Table 3 collets the errors produced.

(a)

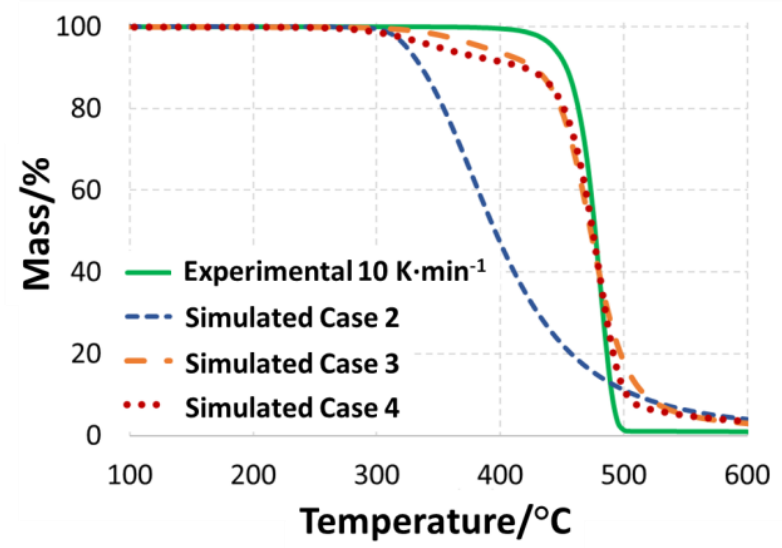

(b)

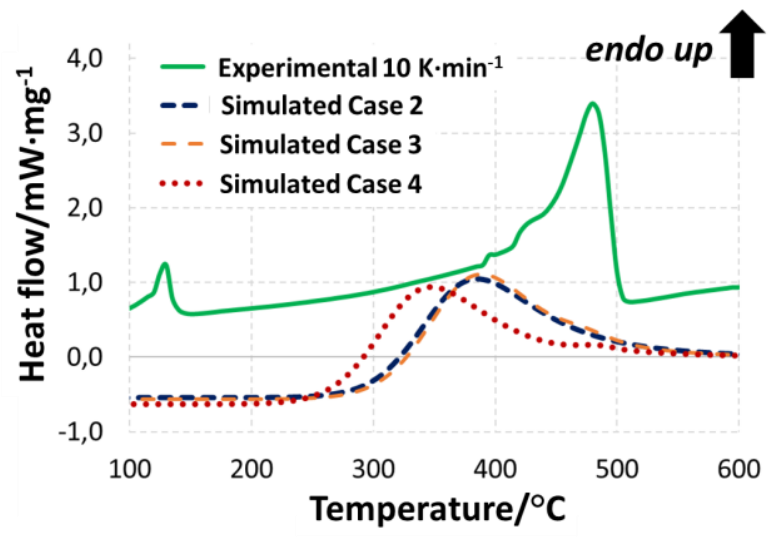

Fig. 4. Results of cases 2 to 4: a TG, b DSC. 
Table 3. Error in cases 2 to 4 .

\begin{tabular}{llllll}
\hline Case & Influence of TG, $\gamma$ & Influence of DSC, $\beta$ & $\hat{X}_{\text {error TG }}$ & $\hat{X}_{\text {error } D S C}$ & Evaluation error function \\
\hline 2 & 0.5 & 0.5 & 1.000 & 0.635 & 0.592 \\
3 & 0.7 & 0.3 & 0.217 & 0.637 & 0.244 \\
4 & 0.9 & 0.1 & 0.191 & 0.651 & 0.184 \\
\hline
\end{tabular}

The fact of considering the DSC error in the analysis reduces the error in DSC curve, since it was required an approaching degree of the simulated DSC curve to the experimental one. On the other hand, TG simulated curve unfits the experimental TG curve with a clear trend, the more influence of DSC, more error of TG.

As seem above, the reaction rate $r_{i j}$ relates the mass loss in Eq. 4 and the energy released in Eq. 6 . The values of the triplet kinetic modify both curves, however, the results reveals the inability to converge both curves simultaneously.

Since we look for fitting DSC curve without affecting TG results, only the heat of reaction could modify the DSC curve without mismatch the TG curve. Therefore, a new case was studied, case 5 . In case 5 the values of the variables from case 1 remains unmodified, so the error in the approaching to TG is minimum and we used the heat of reaction is used as the only variable for the DSC fitting. The results are displayed in Figure 5.

(a)

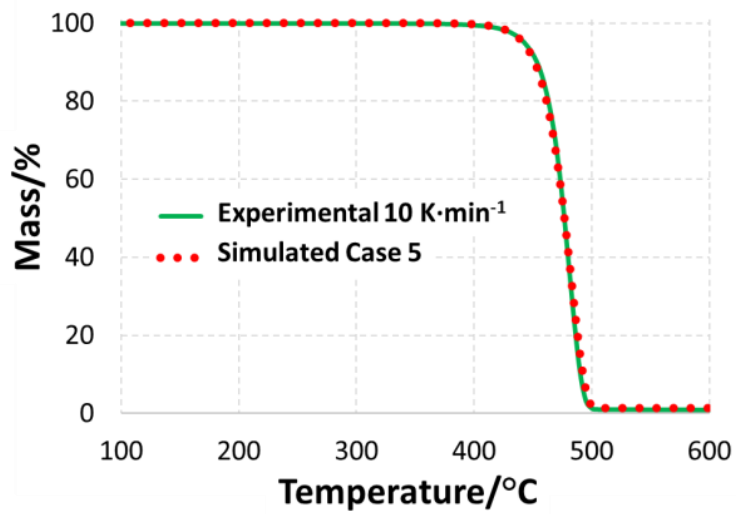

(b)

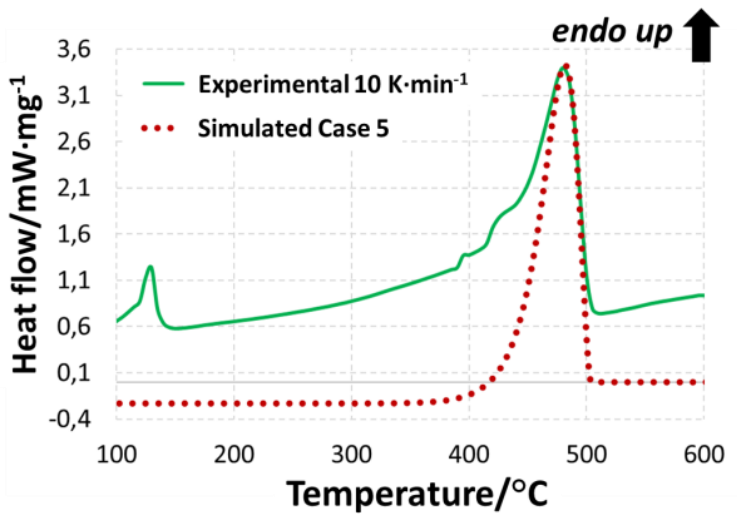

Fig. 5. Results of case 5: a TG, b DSC.

The both simulated curves in Figure 4 are more accurate than any other cases. It must be highlighted that since the curves are estimated separately, the Eq. 12 is not required. Therefore, what is important to assess is the value of the normalized errors for each curve. These values are $\hat{X}_{T G A}^{\text {case }} 5{ }_{\text {error }}=0.032$ and $\hat{X}_{D S C \text { error }}^{\text {case }}=0.581$. Both values represent the lowest errors for all cases.

In other to establish a comparison between all cases, since the evaluation error function and the coefficients $\gamma$ and $\beta$ are discarded in case 5, a global error is calculated using the normalized errors from Eq. 13, i.e. $\hat{X}_{\text {TG error }}^{\text {case } n}$ and $\hat{X}_{D S C \text { error }}^{\text {case }}$, and obtaining the average error. Table 4 gathers the errors for all cases analyzed.

Table 4. Normalized errors for cases 1 to 5 and average errors.

\begin{tabular}{llll}
\hline Case & Normalized TG error & Normalized DSC error & Average error \\
\hline 1 & 0.032 & 1.000 & 0.516 \\
2 & 1.000 & 0.635 & 0.817 \\
3 & 0.217 & 0.637 & 0.426 \\
4 & 0.191 & 0.651 & 0.421 \\
5 & 0.032 & 0.581 & 0.306 \\
\hline
\end{tabular}

The method employed in case 5 to approach TG and DSC curves is the most accurate.

Therefore, the best procedure has two steps: firstly, approach the TG curve to obtain the values of triplet kinetic and the thermal properties; and second, estimate the DSC curve setting-up exclusively the heat of reaction of the different reactions. 
This is consistent with the results reported by Table 3, where a clear tendency of the global error is observed. The more influence of the DSC error (case 2) the more error is produced. Hence, in case 4, where the influence of the DSC error is the lowest, the error is 3.2 times smaller than in case 2 .

Table 4 shows a global view of the effect of the inclusion of the DSC curve in the approaching process. In case 1, only TG is taken into account in the approaching process, therefore, a lower error for the TG curve is obtained, but on the contrary, a bad approach to DSC curve. As result, the average error has a high value. In case 2, where both curves have same influence, the error in DSC curve decrease its value. By the contrast, the TG curve is less accurate than in case 1. As Table 3 shows, the less influence in the approaching process of the DSC error, the less average error. Finally, the errors in case 5, are the smallest obtained.

To confirm and validate the methodology of case 5, a new approach (case 6) was done with three heating rates simultaneously $\left(2,5\right.$ and $\left.10 \mathrm{~K} \cdot \mathrm{min}^{-1}\right)$ following the workflow of case 5 . First step, the approaching to TG curves lead us to obtain the kinetic parameters and thermal properties except the heat of reaction. The error function Eq. 14 is similar to Eq. 12 but slightly modified to assess the three TG curves from their heating rates simultaneously:

$$
\text { Evaluation error function }{ }_{T G}^{3 \text { heating rates }}=\sqrt{\left(X_{\text {error } T G}^{H R 1}\right)^{2}+\left(X_{\text {error } T G}^{H R 2}\right)^{2}+\left(X_{\text {error } T G}^{H R 3}\right)^{2}}
$$

Second step, employing the values obtained in previous step, an approach to the three DSC curves all at once in order to achieve every values of the heat of reaction. The error function is expressed in Eq. 15:

$$
\text { Evaluation error function }{ }_{D S C}^{3 \text { heating rates }}=\sqrt{\left(X_{\text {error DSC }}^{H R 1}\right)^{2}+\left(X_{\text {error DSC }}^{H R 2}\right)^{2}+\left(X_{\text {error DSC }}^{H R 3}\right)^{2}}
$$

The following Figure 6 and Tables 5 show the results and the value of the variables obtained.

(a)

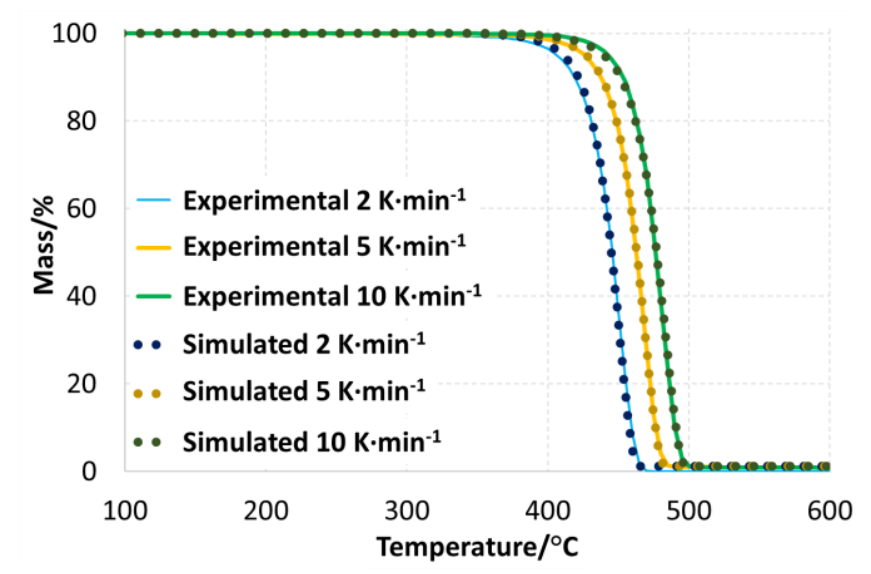

(b)

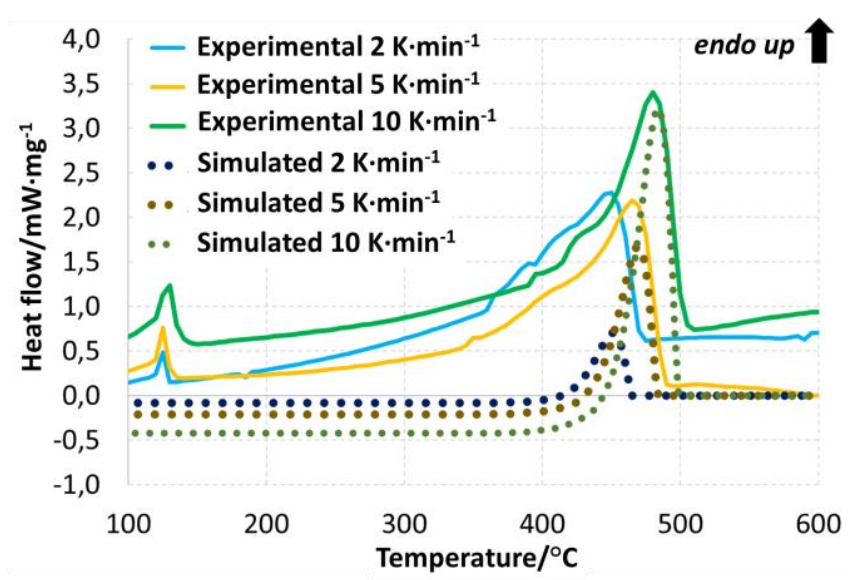

Fig. 6. Results of the simultaneous approach to three heating rates (case 6): a TG, b DSC.

Table 5. Values of the variables obtained from the approach of case 6.

\begin{tabular}{llll}
\hline Variable & Material A & Material B & Residue \\
\hline Pre exponential factor $(\log 10 A) / \mathrm{s}^{-1}$ & 12.268 & 15.036 & - \\
Activation energy $\left(E_{a}\right) / \mathrm{kJ} \cdot \mathrm{kmol}^{-1}$ & $2.131 \mathrm{e}+5$ & $1.561 \mathrm{e}+5$ & - \\
Reaction order $(n) /-$ & 0.605 & 0.587 & - \\
Heat of reaction $\left(H_{r}\right) / \mathrm{kJ} \cdot \mathrm{kg}^{-1}$ & -400 & -300 & - \\
$v_{p}^{1} /-$ & 0.742 & - & - \\
$v_{r}^{2} /-$ & - & 0.016 & 1.500 \\
Specific heat $\left(C_{p}\right) / \mathrm{kJ}^{-} \mathrm{kg}^{-1} \cdot \mathrm{K}^{-1}$ & 2.550 & 2.550 & 0.200 \\
Conductivity $(k) / \mathrm{W} \cdot \mathrm{m}^{-1} \cdot \mathrm{K}^{-1}$ & 0.300 & 0.300 & 0.850 \\
Emissivity $(\varepsilon) /-$ & 0.850 & 0.850 & \\
\hline
\end{tabular}


The method employed in case 6 allowed to obtain a unique set of variables to characterize the thermal decomposition of the LLDPE. All simulated TG curves describes with a suitable degree of accuracy the experimental ones. The reaction scheme proposed is appropriate to describe the process and any variation of the mass can be represented.

However, the results reveal the influence of the DSC curve and the fact that the approaching of the DSC curve is significantly more complex than the TG ones. As previous cases showed, the simulated DSC curves cannot reproduce the experimental curves with the same level precision. Although the thermal decomposition model is able to simulate TG curves; it did not manage to handle at all the energy released

\section{Conclusions}

The present paper aims to study the possibility of adding the DSC energy released as a new target in the process of determining the kinetic parameters and thermal properties for fire simulation of the LLDPE.

To establish the reaction scheme of the decomposition process, the D2TG method is utilized. This method identifies the number of reactions, the temperatures at which they occur, and consequently, their sequence. It is based on the variations of the rhythms of mass loss with the temperature. Those variations can be observed in the second derivative of the mass curve. A variation of the mass loss rate identifies the debut of a new reaction. The D2TG method establishes a two-consecutive reaction scheme for the LLDPE decomposition. To assess how accurate the proposed reaction scheme is, a first approximation (case 1), using the TG curve as unique target is carried out. The results prove that the reaction scheme are useful to simulate the TG experimental curve.

The DSC curve is then included as target to optimize, in combination with the TG curve, analyzing three cases (cases 2 to 4). Each case has different level of influence over the analysis i.e. the evaluation error function (Eq. 12). Two conclusions can be made. Applying this method, the DSC curve cannot be modelled with the same level of accuracy as TG curve does. The DSC approximation process unfits the TG approaching, in fact, the more influence of DSC over Eq. 12, the less precision of the TG as Table 3 gathers.

The case 5 employs a different strategy in the approximation process. A first approach to TG curve, as in case 1, is carried out. Afterwards, and maintaining all the values of the variables obtained in the first approach except the heat of reaction, the heat of reaction is modified to achieve the DSC curve. This case makes the lowest error in both curves, and overall, the lower average error (Table 4). The simultaneous analysis of three heating rates from case 6 verifies the methodology used in case 5.

The method to obtain experimental values of both the DSC and TG implies a more complex process to assess only the TG. This process is highly influenced by boundary conditions or the material itself [58, 59], hence, the DSC curve should be taking into account more as qualitative mode, than quantitative. In [60] is recommended to employ the information from DSC as the same mode. To sum up, the values obtained from the TG curve approach have more relevance than the obtained from DSC curve. Uniquely the heat of reaction obtained from DSC should be taken into account.

The DSC curve gathers more complex information than the variation of the mass, such as glass transitions, heat of fusion, heat of reaction, melting temperature, phase changes, etc. If two or more reactions are overlapped, e.g. if one reaction is not finished completely and next reaction has already started, the energy released will not be modelled properly as a simple sum of energies, as TG does with the mass.

The alterations in energy measured by the DSC signal have different sources, some of them comes from process that not implies variation of the mass e.g. glass transitions, heat of fusion etc. The Eq. 6 assesses the energy, which has a straight relation to the mass variation $\left(r_{i j}\right)$. Therefore, those thermal processes, which are not related with variation of the mass, cannot be reproduced accurately. Figure $6 \mathrm{~b}$ shows that energy absorbed due the melting process (approx. at $105^{\circ} \mathrm{C}$ [61]) is not represented. Same issue is repeated from the beginning of the tests up to $350^{\circ} \mathrm{C}$, where the masses of three curves remain constant (Figure 1 a) but the DSC values not. 


\section{Acknowledgements}

Authors would like to thank to the Consejo de Seguridad Nuclear for the cooperation and co-financing the project "Simulation of fires in nuclear power plants" and to CAFESTO Project funded by the Spanish Ministry of Science, Innovation and Universities and the Spanish State Research Agency through Public-Private Partnerships (Retos Colaboración 2017 call, ref RTC-2017-6066-8) co-funded by ERDF under the objective "Strengthening research, technological development and innovation".

\section{References}

1. Ozawa T. Thermal analysis - review and prospect. Thermochim. Acta. 2000; 355(1-2): 35-42.

2. Kissinger HE. Reaction Kinetics in Differential Thermal Analysis. Anal. Chem. 1957; 29(11): $1702-6$.

3. Laidler KJ. The development of the Arrhenius equation. J. Chem. Educ. 1984; 61(6): 494.

4. Lautenberger C, Fernandez-Pello C. Generalized pyrolysis model for combustible solids. Fire Saf. J. 2009; 44(6): 819-839.

5. Stoliarov S, Lyon R. Thermo-Kinetic Model of Burning for Pyrolyzing Materials. Fire Safety Science. 2008; 9: 11411152 .

6. Chaos M, Khan MM, Krishnamoorthy N, de Ris JL, Dorofeev, SB. Evaluation of optimization schemes and determination of solid fuel properties for CFD fire models using bench-scale pyrolysis tests. Proceedings of the Combustion Institute. 2011; 33(2): 2599-2606.

7. Snegirev AY, Talalov VA, Stepanov VV, Harris JN. A new model to predict pyrolysis, ignition and burning of flammable materials in fire tests. Fire Saf. J. 2013; 59: 132-150.

8. McGrattan K, Hostikka S, McDermott R, Floyd J, Vanella M. Fire Dynamics Simulator Technical Reference Guide Vol.1. NIST Special Publication 1018-1. Sixth Edition. 2018.

9. Rotaru A, Goşa M, Rotaru P. Computational thermal and kinetic analysis. J. Therm. Anal. Calorim. 2008; 94(2): 367371.

10. Rotaru A, Goşa M. Computational thermal and kinetic analysis. J. Therm. Anal. Calorim. 2009; 97(2): 421-6.

11. Haines PJ. Principles of thermal analysis and calorimetry. Royal society of chemistry, 2002.

12. Erceg M, Krešić I, Vrandečić NS, Jakić M. Different approaches to the kinetic analysis of thermal degradation of poly(ethylene oxide). J. Therm. Anal. Calorim. 2017; 131(1): 325-334.

13. Liu J, Song D, Guan H. Isothermal kinetics approach to investigating the oxidation process of red phosphorus in air. J. Therm. Anal. Calorim. 2017; 128(3): 1801-1810.

14. Agarwal G, Liu G, Lattimer B. Pyrolysis and Oxidation of Cardboard. Fire Safety Science. 2014, 11: $124-137$.

15. Roduit, B. Computational aspects of kinetic analysis. Thermochim. Acta. 2000; 355(1-2): 171-180.

16. Trache D, Abdelaziz A, Siouani B. A simple and linear isoconversional method to determine the pre-exponential factors and the mathematical reaction mechanism functions. J. Therm. Anal. Calorim. 2018; 128(1): 335-348.

17. Marian E, Tita B, Tita IC, Jurca T, Vicas L. Thermal behaviour and kinetic study of amygdalin. J. Therm. Anal. Calorim. 2018; 134(1): 765-772.

18. Salmani M, Alamdari EK, Firoozi S. Isoconversional analysis of thermal dissociation kinetics of hematite in air and inert atmospheres. J. Therm. Anal. Calorim. 2017, 128(3): 1385-1390.

19. Roduit B, Xia L, Folly P, Berger B, Mathieu J, Sarbach A, Andres H, Ramin M, Vogelsanger B, Spitzer D, Moulard $\mathrm{H}$, Dilhan D. The simulation of the thermal behavior of energetic materials based on DSC and HFC signals. J. Therm. Anal. Calorim. 2008; 93(1): 143-152.

20. Wang Z, Wei R, Ning X, Xie T, Wang J. Thermal degradation properties of LDPE insulation for new and aged fine wires. J. Therm. Anal. Calorim. 2018.

21. Chen R, Xu X, Zhang Y, Lo S, Lu S. Kinetic study on pyrolysis of waste phenolic fibre-reinforced plastic. Appl. Therm. Eng. 2018; 136: 484-491.

22. Ferreiro AI, Rabaçal M, Costa M. A combined genetic algorithm and least squares fitting procedure for the estimation of the kinetic parameters of the pyrolysis of agricultural residues. Energy Convers. Manag. 2016; 125: 290-300.

23. Hasalová L, Ira J, Jahoda M. Practical observations on the use of Shuffled Complex Evolution (SCE) algorithm for kinetic parameters estimation in pyrolysis modeling. Fire Saf. J. 2016; 80: 71-82.

24. Lautenberger C, Fernandez-Pello C. Optimization Algorithms for Material Pyrolysis Property Estimation. Fire Safety Science. 2011, 10: 751-764. 
25. Rein G, Lautenberger C, Fernandez-Pello C, Torero JL, Urban DL. Application of genetic algorithms and thermogravimetry to determine the kinetics of polyurethane foam in smoldering combustion. Combust. Flame. 2016; 146(1-2): 95-108.

26. Capote J, Alvear D, Abreu O, Lazaro M, Puente E. Pyrolysis Characterization of a Lineal Low Density Polyethylene. Fire Safety Science. 2011; 10: 877-888.

27. Lautenberger C, Rein G, Fernandez-Pello C. The application of a genetic algorithm to estimate material properties for fire modeling from bench-scale fire test data. Fire Saf. J. 2006; 41(3): 204-214.

28. Webster RD. Pyrolysis Model Parameter Optimization Using a Customized Stochastic Hill- Climber Algorithm and Bench-Scale Fire Test Data. MS Thesis, Department of Fire Protection Engineering, University of Maryland. 2009

29. Stoliarov SI, Walters RN. Determination of the heats of gasification of polymers using differential scanning calorimetry. Polym. Degrad. Stab. 2008; 93(2): 422-427.

30. Lautenberger C, Kim E, Dembsey N, Fernandez-Pello C. The Role of Decomposition Kinetics in Pyrolysis Modeling - Application to a Fire Retardant Polyester Composite. Fire Safety Science. 2008; 9: 1201-1212.

31. Li J, Stoliarov SI. Measurement of kinetics and thermodynamics of the thermal degradation for non-charring polymers. Combust. Flame. 2013; 160(7): 1287-1297.

32. Li J, Stoliarov SI. Measurement of kinetics and thermodynamics of the thermal degradation for charring polymers. Polym. Degrad. Stab. 2014; 106: 2-15.

33. Stoliarov SI, Li J. Parameterization and Validation of Pyrolysis Models for Polymeric Materials. Fire Technol. 2016; 52(1): 79-91.

34. Li J, Gong J, Stoliarov, SI. Development of pyrolysis models for charring polymers. Polym. Degrad. Stab. 2015; 115: 138-152.

35. McKinnon MB, Stoliarov SI, Witkowski, A. Development of a pyrolysis model for corrugated cardboard. Combust. Flame. 2013; 160(11): 2595-2607.

36. Li KY, Pau DSW, Hou YN, Ji J. Modeling Pyrolysis of Charring Materials: Determining Kinetic Properties and Heat of Pyrolysis of Medium Density Fiberboard. Ind. Eng. Chem. Res. 2013; 53(1): 141-149.

37. Alonso A, Puente E, Lázaro P, Lázaro D, Alvear D. Experimental review of oxygen content at mixing layer in cone calorimeter. J. Therm. Anal. Calorim. 2017; 129(2): 639-654.

38. ASTM-E1131-08. Standard Test Method for compositional analysis by thermogravimetry. ASTM International. 2014.

39. Zong R, Wang Z, Liu N, Hu Y, Liao G. Thermal degradation kinetics of polyethylene and silane-crosslinked polyethylene. J. Appl. Polym. Sci. 2005; 98(3): 1172-1179.

40. Al-Salem SM, Bumajdad A, Khan AR, Sharma BK, Chandrasekaran SR, Al-Turki FA, Al-Dhafeeri AT. Nonisothermal degradation kinetics of virgin linear low density polyethylene (LLDPE) and biodegradable polymer blends. J Polym Res. 2018; 25(5): 111.

41. Dollimore D, Tong P, Alexander KS. The kinetic interpretation of the decomposition of calcium carbonate by use of relationships other than the Arrhenius equation. Thermochim. Acta. 1996, 282-283: 13-27.

42. Peterson JD, Vyazovkin S, Wight CA. Kinetics of the thermal and thermo-oxidative degradation of polystyrene, polyethylene and poly (propylene). Macromol. Chem. Phys. 2001; 202(6): 775-784.

43. Aboulkas A, El harfi K, El Bouadili A. Thermal degradation behaviors of polyethylene and polypropylene. Part I: Pyrolysis kinetics and mechanisms. Energy Convers. Manag. 2010; 51(7): 1363-1369.

44. Marcilla A, Beltrán M. Kinetic study of the thermal decomposition of polystyrene and polyethylene-vinyl acetate graft copolymers by thermogravimetric analysis. Polym Degrad Stab. 1995; 50(1): 117-124.

45. Lázaro D, Puente E, Lázaro M, Alvear, D. Characterization of Polyethylene Decomposition Reactions Using the TG Curve. IRECHE. 2014; 6(1): 77-82

46. Li K-Y, Huang X, Fleischmann C, Rein G, Ji J. Pyrolysis of Medium-Density Fiberboard: Optimized Search for Kinetics Scheme and Parameters via a Genetic Algorithm Driven by Kissinger's Method. Energy Fuels. 2014; 28(9): 6130-6139.

47. Ding Y, Wang C, Chaos M, Chen R, Lu S. Estimation of beech pyrolysis kinetic parameters by Shuffled Complex Evolution. Bioresour. Technol. 2016; 200: 658-665.

48. Duan Q, Sorooshian S, Gupta V. Effective and efficient global optimization for conceptual rainfall-runoff models. Water Resour. Res. 1992; 28(4): 1015-1031

49. Jiang Y, Gong S. Bus holding strategy based on shuffled complex evolution method. Front. Comput. Sci. 2012; 6(4): 462-468.

50. Chen Z, Liu L, Li L, Li H. A two-stage model for project optimization in transportation infrastructure management system. Math. Probl. Eng. 2014:1-8. 
51. Vrugt JA, Gupta HV, Bouten W, Sorooshian S. A Shuffled Complex Evolution Metropolis algorithm for optimization and uncertainty assessment of hydrologic model parameters. Water Resour. Res. 2003; 39(8).

52. Van Griensven A, Bauwens W. Multiobjective autocalibration for semidistributed water quality models. Water Resour. Res. 2013; 39(12).

53. Chaos M, Khan MM, Krishnamoorthy N, de Ris JL, Dorofeev SB. Evaluation of optimization schemes and determination of solid fuel properties for CFD fire models using bench-scale pyrolysis tests. Proceedings of the Combustion Institute. 2011; 33(2): 2599-2606.

54. Duan QY, Gupta VK, Sorooshian S. Shuffled complex evolution approach for effective and efficient global minimization. J Optim Theory Appl. 1993; 76(3): 501-521.

55. Nelder JA, Mead R. A simplex method for function minimization. Comput. J. 1965; 7(4): 308-313.

56. Shanks RA, Amarasinghe G. Crystallisation of blends of LLDPE with branched VLDPE. Polymer. 2000; 41(12): 4579-4587.

57. An Q, Qi S, Zhou W. Thermal, electrical, and mechanical properties of Si3N4 filled LLDPE composite. Polym. Compos. 2009; 30(7): 866-871.

58. Comesaña R., Gómez MA, Álvarez MA, Eguía P. Thermal lag analysis on a simulated TGA-DSC device. Thermochim. Acta. 2012; 547: 13-21.

59. Lázaro D, Lázaro M, Alonso A, Alvear D. Effects of boundary conditions variation on chemical reactions during STA measurements. Proceedings of the International Conference Research and advanced Technology in fire Safety. University of Cantabria. 2017.

60. Matala A. Methods and applications of pyrolysis modelling for polymeric materials. VTT Technical Research Centre of Finland. 2013.

61. Cardarelli F. Materials handbook: A concise desktop reference. Springer Science \& Business Media. 2008. 